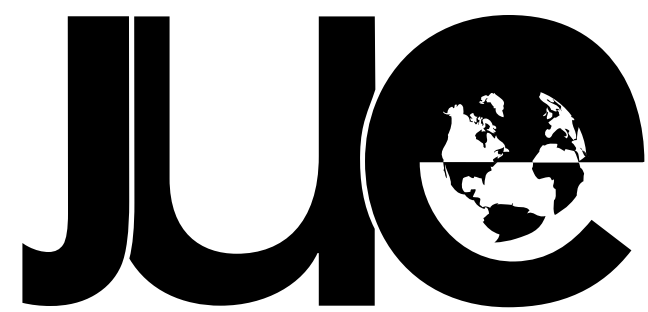

The Journal for Undergraduate Ethnography

Issue I. Spring 201।

\title{
Acknowledging the Stigmatized: Sex Offenders and Their Outlooks Versus Women in Relationships with Incarcerated Men and their Perceptions of the Criminal Justice System
}

Caroline Womer

UNIVERSITY OF DELAWARE, CAROLINEWOMER@GMAL.COM

\section{Abstract}

Offenders are a stigmatized group of individuals, making it difficult for society to proffer second chances so willingly. Furthermore, many women in relationships with offenders suffer the stigma that offenders themselves experience. This study offers a theoretical contribution that focuses mostly on sex offenders in an attempt to help reshape their perceptions and bring clarity to an existing theoretical framework. Sex offenders' outlooks were examined and placed into a threeschema approach (instrumental, political, and cultural schemas), implemented from a previous study, based on their overall mentality and how they have rationalized their offenses. Similarly, women's perceptions of the criminal justice system, based on society's views toward their relationship with an offender, were categorized into the three schemas to contrast the varying types of stigma. In this study, about 40 letters from sex offenders, as well as select stories from a book containing sex offender accounts, were coded and analyzed under this framework using Atlas-ti. Additionally, twelve interviews were carried out with women in relationships with incarcerated men. Results suggest that while many sex offenders desire change, they do not take full responsibility for their actions, meaning that these particular offenders' outlooks do not fit neatly into one schema. A fourth schema, christened the "chimerical schema", is proposed to further explain offenders' outlooks. Mostof the women's perceptions, however, easily fit into one of the three schemas, rendering the fourth schema unnecessary. This study will add to an existing theoretical framework, making it more applicable to other marginalized groups.

Sex offenders are a stigmatized population within our country's justice system. In this study, I sought to unveil the mystery surrounding this elusive group of individuals and attempted to categorize their method of thinking in regards to the criminal justice system, rehabilitation, current laws, and overall outlook on their own offenses. Furthermore, I explored why sex offenders feel a compelling need to rationalize their offenses. In addition to these categories,
I made an effort to juxtapose this stigma felt by sex offenders with the stigma thatsociety imposes on women in relationships with a broad array of incarcerated men. I felt that first-hand interviews with women in relationships with offenders enhanced the concept of stigmatization as a whole and provided supplementary views regarding our country's criminal justice system. Using a framework provided by Idit Kostiner in her article, "Evaluating Legality: 
Toward a Cultural Approach to the Study of Law and Social Change," three schemas were uncovered that she found to be applicable to social activists and how they utilize the law to achieve social change (Kostiner 2003). I adopted this framework and applied the three-schema approach to sex offenders; based on their outlooks of their own offenses, I categorized them into one of the three schemas Kostiner provided. On a smaller scale, I applied the three schemas to women's perceptions of the American criminal justice system based on how society viewed their relationships with incarcerated offenders. Throughout the course of this study, I attempted to determine which of the three schemas a majority of sex offenders seemed to fall under and, when applicable, why and how sex offenders rationalize their offenses. I compared this with the stigma felt by women in relationships with offenders to further express the judgments that society passes on varying groups of individuals.

\section{SELECTED LITERATURE REVIEW}

The bulk of literature applicable to my research was Pamela Schultz's Not Monsters (2005) and Hanson and Slater's "Reactions to Motivational Accounts of Child Molesters" (1993). While this is a rather selective literature review, both of these contributed a vast amount of information to my research and allowed me to peer further into the world of sex offenders. Not Monsters contains accounts from interviews carried out with sex offenders by the author herself. I discovered that in a majority of these accounts, there is an underlying theme of the desire to change, yet unwillingness on the part of the offender to accept responsibility for his actions (Schultz 2005).

In many of the accounts from Not Monsters, offenders used blaming as a rhetorical strategy. Most of them seemed highly unaware they even employed the use of strategies, but in essence, they projected the responsibility of their actions onto other people or ideas. In one of Schultz's interviews, she states that while he displayed little empathy for the children he victimized, the offender made it clear that he held children in such high regard. To combat his projection of blame, Schultz further states, "When I pointed out that pilgrims generally don't rape their deities, he shuddered and convulsively thrust out his hands, as though he wanted to push away the reality of my statement" (2005). Studying the accounts from the sex offenders exposed a predominant theme of denial. Furthermore, another offender stated that, "Most child molesters are in self-denial, and they don't think they committed a crime" (2005). While so many offenders were open about their offenses and could recognize why their actions could be considered wrong, they still felt the need to justify and downplay their offenses to legitimize their rationale to society.

Hanson and Slater's article, "Reactions to Motivational Accounts of Child Molesters," delves into accounts that offenders provided regarding their respective offenses and how certain members of society change their perceptions of an offender and his blameworthiness, depending on how legitimate the account seemed to 
be. From the start, the authors used the example of a juvenile delinquent to convey the strategy of what they call "techniques of neutralization" (Hanson and Slater 1993). "[W] hen delinquents are asked to explain their actions, they will acknowledge that theft, for example, is generally wrong, but point to special circumstances that mitigate the wrongfulness of their actions (e.g., I needed the money, I was drunk, the owner mistreated me, etc.)" (1993). Other researchers documented such "techniques of neutralization' in wife assaulters (Dutton 1986), rapists (Scully and Marolla I98I), and child molesters (De Young 1988; Pollock and Hashmall 1991; Taylor 1972).

In their study, Hanson and Slater found that of their interview pool (consisting of therapists and probation officers), "people are more likely to be accepting of deviant behavior when they perceive the transgression as caused by factors that are external and uncontrollable" (1993). Furthermore, the authors found that "it is likely that an offender who denied molesting a child (despite convincing evidence to the contrary) would receive a more lenient sentence than an offender who admitted to the offense without remorse" (1993). Judging by this observation, it seems that regardless of how culpable an offender actually is, society treats him with a greater degree of empathy when he projects his blame onto other people or circumstances and tries to rationalize his offense. It is apparent that we, as a society, want to believe that offenders have a legitimate excuse for their actions and are truly remorseful. This idea, however, propagates sex offenders' beliefs that rationalizing their offenses is more acceptable to society; in reality, this belief merely evades the truth and creates more problems.

Applying Hanson and Slater's article to Not Monsters, I discovered that while offenders may admit their offense was wrong, they project the blame onto others or focus on other irrelevant scenarios in order to rationalize their offense, thus justifying their actions. In one account from a more irritable offender, he discusses his first time in prison after he was reported by his daughter for sexually assaulting her. He states, "My family did come visit me. But I wouldn't see them. I was kind of angry. What had happened was supposed to be a family issue, but my daughter turned it into a public issue...I said to my daughter, 'You really didn't have to put us through all this"' (Schultz 2005). This case represents a more obvious blaming tactic, especially when the offender tells his daughter that she was essentially at fault for the family's predicament. By attempting to place the blame on someone else, the offender essentially tried to feel like what he did was not as severe as it is in reality. An offender who attempted to rationalize his pedophilia stated the following: “Me, l'm great at rationalizing. I can make myself look good for my own benefit. Being the type of person who doesn't want to hurt anyone or do anything wrong, I could rationalize in a million different ways" (2005). Though disturbing, it is quite interesting to see how this offender coped with his wrongdoings. If he rationalized his offense in a way that made him feel less responsible, he did not feel that he doing anything wrong. Rationalization, although a well-used coping mechanism, can be detrimental, especially when responsibility is not taken for a wrongful action. This is a continuing issue, and 


\section{I placed each offenders' outlook into the most appropriate schema out of the three, hoping to draw conclusions as to how developed offenders are in their viewpoints regarding their offenses.}

as Hanson and Slater point out, "When self-presentation attempts are readily recognized, it becomes possible to identify the offenders' genuinely deviant attitudes, attitudes that may contribute to their criminal behavior" (1993).

\section{METHODOLOGY}

Using Atlas-ti, I coded and analyzed 40 letters from sex offenders as well as accounts from sex offenders coming from Not Monsters. Due to Dr. Chrysanthi Leon's (of the University of Delaware) academic establishment in this field, incarcerated or previously incarcerated sex offenders from across the nation write her on a regular basis in regards to their opinions on current sex offender laws, their hopes of participating in her research, and personal stories about their own offenses and the effect it has on their lives and the lives of others. I coded the most recent letters received by Dr. Leon from spring of 2010, keeping the offenders' identities confidential. As mentioned previously, I implemented Idit Kostiner's three schema approach, from her article "Evaluating Legality: Toward a Cultural Approach to the Study of Law and Social Change," as my theoretical framework. As a brief overview, the three schemas are as follows: the instrumental schema is a desire for a change of concrete resources, the political schema is one that seeks to empower marginalized groups/communities and rally forces, and lastly, the cultural schema seeks to transform assumptions made by typical society. While Kostiner used these schemas to categorize those involved in social activism, I applied them to sex offenders.
I began the coding process by extracting the offenders' outlooks on their own offense from the letters and, once found, coded for words and phrases most applicable to the three schemas, offender rationalization, any type of stigma that was encountered, and any other emotions expressed by the offender that stood out to me. Some of the main words, concepts, and phrases I searched for included: blaming, desire for change, denial, empowerment, anger toward the political power structure or toward those directly or indirectly involved with the offender, and a desire to change others' opinions. Upon completing the process of coding the letters, I placed each of the offenders' outlooks into the most appropriate schema out of the three, hoping to draw conclusions as to how developed offenders are in their viewpoints regarding their offenses. Since the cultural schema is the most ideal schema for sex offenders to embrace, due to the fact that it encompasses an acceptance and responsibility that surpasses the characteristics of the other two schemas, an analysis of the offenders' letters was the first major step in determining where offenders fit in categorically. Due to the nature of these three schemas, however, they are not mutually exclusive. While my initial goal was to place offenders' outlooks into only one of the three categories, some of them embodied more than one.

In order to execute the interview process for women in relationships with incarcerated offenders, I borrowed names from an existing research study that was being carried out by graduate student Laura Rapp and Dr. Chrysanthi Leon of the University of Delaware. Over the course of about two months, another graduate student 
and I set up phone interviews with women interested in participating in the study. We amended a questionnaire from Rapp and Leon's study to better suit our own research objectives and asked the women a range of questions including, but not limited to, their childhood, their relationship, the impact that their significant other's conviction has had on their life, how others in their life have reacted to their relationship, and how involved they are in any advocacy groups. The interviews were generally structured, but any questions, concerns, or additional thoughts from the women were welcomed.The women's identities remained confidential. We conducted twelve interviews. Upon concluding the interview process, I used the information I obtained and categorized the women's outlooks into each of the three schemas based on how they viewed the criminal justice system in terms of how they felt society perceived them for their relationship.

Similar to Kostiner, I carried out an interpretivist study. As she states in her article, "While survey methodology is another way to studying culture, it is more limited in its ability to capture the richness and subtleties of culture" (Kostiner 2003). Ann Chih Lin captures the perks of interpretivist research perfectly in her article "Bridging Positivist and Interpretivist Approaches to Qualitative Methods," and states that, "[Interpretivist research] can seek to...uncover the conscious and unconscious explanations people have for what they do or believe, or to capture and reproduce a particular time, culture, or place so that actions people take become intelligible" (Lin 1998). I concerned myself with tying theory to one's experiences rather than generalizing attitudes. While I cannot draw conclusions across the board in regards to sex offenders and their outlooks, I can find meaning within the accounts that I analyzed and better understand why sex offenders rationalize their offenses to such a degree. My research is case specific. While an interpretivist approach makes it difficult to suggest policy implications or generalize to the entire population of sex offenders and women in relationships with offenders as a whole, I am seeking to make a contribution to the theoretical realm of academia rather than public policy. The bulk of my research is not generalizable, focusing on identifying with the sex offender community and attempting to see the world as they do.

Although I was unable to interview the sex offenders, I gathered firsthand accounts through their letters which allowed me to indirectly obtain a greater understanding of this subculture of offenders that society possesses limited access to. By carrying out the interviews with women in relationships with offenders, I was able to better comprehend the stigma that both experience and Kostiner's three schemas as applied to my research. The interviews with the women served as an enhancement to what I discovered from coding the sex offenders' letters. Both, however, were equally crucial in my research; I compared and contrasted each group's general outlook in order to gain a greater understanding of their individual struggles and experiences within our country's criminal justice system. While my research was case specific, it provided a more intimate environment through interviews with women in relationships with offenders and personal letters containing detailed accounts from sex offenders' 
that proved to be more engaging and interactive than a more positivist approach.

\section{DATA}

The schemas are crucial in my study and applicable in regards to sex offenders. Within her framework, Kostiner explained the complementary characteristics of the law and achieving social change. Applying her findings to sex offenders proved quite fascinating; the voice of sex offenders, unlike other marginalized groups, is a voice that society rarely listens to. By utilizing the three schemas, however, I found that many of the offenders' voices go unheard due to how they portray themselves to society. By conforming to a more understanding and transformative approach, sex offenders may be able to obtain a voice in society and address issues regarding public policy. In her article, Kostiner challenges what she finds to be legal myths and states that more often than not, many "legal doctrines are ideologically biased in support of status quo hierarchies. Due to this ideological bias, these studies see that use of legal norms and tactics as preventing or co-opting the struggles of marginalized groups" (Kostiner, 2003). It is depicted here that many of these so-called "rights" are doing more harm than good. By challenging these ideas and regrouping sex offenders' outlooks into various schemas, society can begin to view offenders in a different light and rethink some of the policies that we, as a society, believe to be effective, when in actuality, they are often not.

\section{INSTRUMENTAL SCHEMA}

Probing further into Kostiner's framework, the three schemas are presented in more detail. The instrumental schema is the least developed of the schemas and possesses very basic characteristics. This schema focuses on the needs of the individual, and success is seen when efforts lead to change. Social power is not a motivation here; there is an underlying goal of serving others in need and a desire to help. Additionally, there is a focus on concrete (and often material) needs; often times they attempt to justify these needs with demands. Basic strategies of this schema include service and policy advocacy (Kostiner 2003).

To reflect this sentiment, I coded many accounts of the instrumental schema as exhibited in the sex offender letters. One offender stated, "I am a college student... and am presently enrolled in a sociology class...I do hope that your research helps to correct the many problems associated with how our government treats sex offenders." In this instance, the heart of the instrumental schema's characteristics shines through. While the offender desires change for himself, he makes it clear that there is a concrete need for change among sex offenders as a whole. He expresses hope that the research will lead to a different societal attitude toward sex offenders; this brings to the table the idea that success is seen in the solution-one of the main themes of the instrumental schema.

Another offender expresses his interest in Dr. Chrysanthi Leon's research and states, "I am an offender 


\section{In regards to women in relationships with offenders, many viewed the criminal justice system from the instrumental perspective.}

serving a 25 year sentence. I believe much of the information that is used to make legal decisions and shape social views pertaining to sex offenders is inaccurate and/ or misleading. I truly believe that a result of this can be an increase in offenses and an increase in the number of victim deaths." Similar to the first offender, this offender is also interested in public policy and stresses the need for change and a focus on societal needs. Additionally, the need for success is present; the offender believes that without a concrete solution, there will be no successful result.

In regards to women in relationships with offenders, many viewed the criminal justice system from the instrumental perspective. All of the women interviewed stated that at some point, and to varying degrees, they felt judged by society; often times, the people in their lives would simply deny their relationship's existence-even families. One woman went so far as to say that " $[t]$ hey try to say they understand, but they haven't got a clue. They don't even try.They just think that maybe it's a phase, or... they just don't really talk about it anymore. It makes them very uncomfortable." Many women whose outlooks fit into this schema discussed the need for a modification of the corrections system and sincerely believed that change would not come unless this first occurred.

A large amount of the women whose outlooks fit into the instrumental schema, however, expressed the characteristics of service and advocacy. A fair number of the women interviewed involve themselves in Citizens United for Rehabilitation of Errants (CURE), an organization that promotes the rights of prisoners and a criminal justice system that is conducive to rehabilitation. Many of these women selflessly donate their time to advocacy organizations and often drive hundreds of miles to visit their boyfriends or spouses in prison. This desire to help and to be an active member and advocate for prisoner's rights is one of the defining features of the instrumental schema.

\section{POLITICAL SCHEMA}

While the political schema seems more developed than the instrumental schema, the two differ in a variety of ways. Instead of the instrumental schema's indifference to social power, the need for social power is a strong underlying theme of the political schema. Emphasis is placed on the political power structure and the need to oppose it. The political schema opposes power structures and oppression because they view power as the source of inequality and injustice. For those who claim to be a part of this schema, anger often acts as the motivator and the goal is to empower marginalized groups. It is not an individual concept-this schema stresses mass movements and united fronts. Organization is another main theme (Kostiner 2003).

While more developed than the instrumental schema in that its characteristics are more complex and require a higher level of organization, the political schema possesses a more intense nature and a stronger focus on opposition. One offender states that "[t]he important thing is that you are doing research that will hopefully someday 


\section{Clear signs point subtly toward this woman's embodiment of the anger and bitterness that often accompanies the political schema, but it is fleeting.}

help cut down on the hysteria that the media and the politicians are instigating so that they can scare the public and get votes in the next election." As depicted here, the offender expresses feelings of bitterness and hostility toward the political power structure. Motivated by his feelings of anger and distrust, he believes that politicians are unjust and they feel the need to oppress groups of people for political gain. This is a common sentiment among members of the political schema; one in rooted in bitterness and aimed at gaining more control over a situation.

None of the women in the relationship study directly expressed any facets of the political schema. When I asked one woman how she reacted to society's ignorance regarding her relationship, she responded by stating,"I used to get really upset and angry. And I used to get really drunk. But you know I wasn't getting anywhere and I had to stop..." Clear signs point subtly toward this woman's embodiment of the anger and bitterness that often accompanies the political schema, but it is fleeting. She did not express opposition or a strong desire on her part to achieve social power. In no way did she express a need to organize groups or movements to protest society's treatment of these women or their incarcerated significant others.

\section{CULTURAL SCHEMA}

Lastly, the cultural schema is the most ideal and what Kostiner believes social activists should strive to achieve. This schema adopts a globalized perspective and attempts to embrace and encompass all views. Members of this schema believe that injustice is a result of society's misconception of marginalized and oppressed groups. Here, the goal is to expose and transform these biases into understanding. This schema, like the political schema, discourages opposition and replaces it with a strong focus on thinking, which allows for a more tender approach. Members of the cultural schema believe that change only occurs when their method expresses a message of love and respect and when it ties to personal experience (Kostiner 2003).

Unlike the instrumental schema, the cultural schema does not measure success by immediate change. Instead, members of this schema are more long-term goaloriented, realizing that change takes time (Kostiner 2003). One offender recently wrote, "I am very interested in being researched as I want the truth out...Ideally, if I'm released l'll be able to participate in a more thorough and detailed research of pedophiles to prove that we're not harmful or dangerous...I want you to know l'll be open and honest and only want the truth to come out so that the public will learn the truth. Thanks so much for doing this." While traces of the instrumental schema exist here, this offender exceeds this schema's characteristics and embraces a more personal and understanding ideology. The offender takes note that change is a long process, therefore, motivating him to be truthful regarding his offense in order to hopefully transform what he believes to be society's misconception regarding sex offenders. He expresses his gratitude toward the study and making it easier for one to believe that he accepts full responsibility 
for his actions and desires not only a change in society, but in himself as well. Unlike members of the political schema, society would certainly be more willing to listen to offenders categorized in the cultural schema.

Judging by the fact that the cultural schema is a more advanced and developed version of the instrumental schema, it is no surprise that many of the women in the relationship study fit this schema as well. Many of these women's lengthy involvements in the criminal justice system, whether it be as a corrections officer or attending hearing upon hearing for her significant other, brought about the realization that change is not only a necessity in the criminal justice system, but also a gradual process. Most of the women fitting into this schema accepted the fact that society misconstrued their relationships with incarcerated offenders. In taking a more loving approach toward society, one woman stated, “I don't need to alienate the world because there may come a point in time where I really need them...they know that I've been with him [her boyfriend] all this time and that he's a very important part of my life whether they acknowledge it or not." Contrary to the political schema, this woman takes a more optimistic approach and realized that while society may not accept her now, taking the time to be patient with them may pay off long-term.

Furthermore, a large portion of the cultural schema focuses on transforming society's misconceptions of biases - in this case, incarcerated offenders and the women who choose to be in relationships with them. The same woman spoke about how she coped with society's discomfort toward her relationship and said, "I've just learned that I really have to try and let it go. I'm not going to change anybody. I can't convict them or change them or even convince them that they need to see things my way...l've just come to the point where I just kind of live with it and I don't press the issue-I don't push it on them anymore. Now if they ask, that's one thing. But I'm not going to force it on them because they're just too uncomfortable with it." While she clearly wishes to transform society's prejudices into understanding, she realizes that she cannot change their opinions suddenly and that change is gradual. She believes it may not come. The fact that she is at peace with this concept speaks volumes about how most of these women cope with society's judgments.

\section{CHIMERICAL SCHEMA}

Consequently, I found that although I could place many of the sex offenders in one of the three schemas, they did not all neatly correspond to one of the three. Some encompassed more than one, some embraced one schema more than another, and still others seemed to fit in a different category. Studying and coding the letters from sex offenders in my possession, I established a fourth schema, which I call the chimerical schema. I find this schema better explains a majority of these offenders' outlooks. Accordingly, I found that the chimerical schema did not apply to the women in the relationship study; virtually all of the women fit neatly into the instrumental and cultural schemas. 
The chimerical schema embraces aspects of all three schemas, but is not quite as developed as any of these three due to its scattered nature and overall lack of organization. The main aspect of this schema focuses on the end result due to activism, rather than focusing on the process and what is required to attain the end result. Thus, members of the chimerical schema idealize change and believe it to be instantaneous, rather than the process that it usually is. Members often reflect naïve tendencies and are incredibly unrealistic in their approach. Success in the chimerical schema occurs not only when major change happens (similar to the instrumental schema), but also when society's treatment toward sex offenders becomes revolutionized. Members of this schema see success in the solution, as well as through getting their way with minimum compromise.

Additionally, blame comprises another major aspect of the chimerical schema. As it pertains to my research, I observed in a majority of the letters, as well as in accounts from Not Monsters, that offenders place blame on other people, objects, or ideas in an attempt to elicit sympathy in order to achieve change. Furthermore, like members of the political schema, members of this schema use anger and bitterness as motivators. The chimerical schema often includes ostracized individuals that are alone over the political schema's theme of unity and mass movements. While it is common knowledge that sex offenders are an ostracized and stigmatized group of individuals, offenders fitting into this schema seem more set apart than usualeven from other offenders that they associate with on a day to day basis.
While the chimerical schema shares many similarities with the political schema in regards to opposition and bitterness, it differs in that the political schema does not strongly stress change.This fourth schema, though agreeing with the political schema's theme of opposition, stresses change. Change is difficult to come by, however, due to the introverted and isolated nature of the members of this schema. The political schema is largely characterized by unified organization (as opposed to individual efforts) and mass movements. Since the chimerical schema lacks this important quality, the sex offenders' ideation of change becomes more unrealistic. When members realize that change is almost unattainable, they begin to utilize blaming strategies as a defense mechanism and tend to alienate themselves.

Many of the offenders categorized in the chimerical schema did express characteristics from other schemas. As mentioned previously, the schemas are not mutually exclusive; therefore, many offenders fit into more than one schema. I did observe that most of the offenders blatantly displayed characteristics from the newly founded fourth schema. One of the major themes I observed was an offender's attempt to play up his situation in order to evoke the reader's sympathy. In one offender's letter, he states the following: "I want to enumerate the negative, destructive, and lifetime consequences that harsh, callous, merciless, cruel, and inhumane sentence of 17 years 'flattime with no chance of commutation, reduction, or any revocation' l'm currently serving... My wife and my family are devastated emotionally, psychologically, financially, and spiritually...I suffer from a heart condition for which I 


\section{The conflict here is that many offenders possess the desire and will to change, but through justification of their crimes, they do not help their case.}

have a pacemaker implant. My wife has a pacemakerdefibrillator that counters the electrical imbalance in her heart. She NEEDS me to be HOME with her so I can help to manage our family and her daily activities!" While the offender is most likely being honest about his situation at home, the anger and bitterness of his words are quite obvious. His caustic tone is a voice that most of society would likely ignore.

Blame is another prevalent theme in this offender's letter. While the situation regarding his heart condition (as well as his wife's) is unfortunate and rather sad, he utilizes these vices to complain about a crime that he chose to commit. He states that he needs to be home with his wife to assist her; here, the offender attempts to mask his own crime without taking responsibility for his actions and tries to make change come about by using his sick wife as an excuse.Additionally, he blames the criminal justice system for his crime without acknowledging that his action as wrong.

In another letter, an offender goes off on a tangent blaming everyone but himself. He criticizes the police, his lawyer, the judge, and the state of Oklahoma-all without accepting any blame or responsibility for his own actions. Another offender states that "Georgia does not offer treatment for sex offenders...but even if they did, I have no intention of waiting years for a therapist to 'fix me."' In this instance, the offender illustrates his desire for change to occur immediately; he is too impatient to see a therapist for years in order to achieve gradual change and improvement. Change, as displayed in the teachings of the cultural schema, is a process that takes place over an extended period of time.

Rationalization also played a part in my coding process and analysis the offenders' letters. Interestingly, rationalization and blame comprise an essential part of the chimerical schema. Reinforced by Hanson and Slater, I meticulously observed that many offenders made major attempts to rationalize and justify their crimes. The authors explain this phenomenon by stating that, "People who are caught violating social norms typically feel social pressure to explain their transgressions" (Hanson and Slater, 1993). The conflict here is that many offenders possess the desire and will to change, but through justification of their crimes, they do not help their case. When individuals (sex offenders in particular) appear angry about a situation that they need to take responsibility for, society chooses to alienate and ignore them. In addition to this, many offenders grapple with the characteristic of the cultural schema, the desire to transform society's perception of them as a whole. By embracing the lesser-developed chimerical schema, offenders only hurt their case and their chances at achieving public policy that will benefit society as a whole.

\section{DISCUSSION}

The cultural schema, while difficult to attain, is something that sex offenders should attempt to achieve. Sex offenders are a stigmatized group in society and have done little to help their cause. While many offenders embrace the cultural schema, or aspects of it, many 


\section{Even in the brief period of time I spent speaking to these women, I noticed the positivity in their voices and hopefulness in their words.}

others sabotage this decent image of sex offenders by expressing anger, bitterness, blame, justification, and an unwillingness to accept responsibility for their actions. Kostiner highlights one of the important aspects of the cultural schema, "In fact, when activists invoke the cultural schema they find the rhetoric of power to be similarly problematic. In particular, they reject the idea of a struggle between two opposing groups or the rhetoric of 'us against them.' They view such rhetoric as futile, arguing that it only adds negativity to people's thoughts instead of transforming them into positive thoughts of love and respect" (Kostiner, 2003).

It is important to note that while sex offenders are a severely marginalized group in society; ideally, respect should be gained through positive thoughts and without a power struggle. The cultural schema also emphasizes familiarization with one's self and one's desires and beliefs. By learning about and changing oneself, activists can "reach their full potential as people who are striving for social justice" (Kostiner, 2003). Reinforcing Kostiner's view, I find that a movement toward the cultural schema is ideal for sex offenders. This will allow society to begin accepting them as a more understanding group of individuals. Letting go of the chimerical schema and embracing the cultural schema will give offenders the chance to be heard.

Contrary to how sex offenders fit into Kostiner's framework, most of the women in the relationship study already embody the ideal cultural schema. Even in the brief period of time I spent speaking to these women, I noticed the positivity in their voices and hopefulness in their words.
A majority of them eagerly shared their experiences, the stigma they endured, and their views on the nation's justice system. I believe the degree of stigma impressed upon these women versus that of the sex offenders explains this pattern in the data. While the women in this study experience society's judgments and discomfort in regards to their relationships with incarcerated men, they possess a more optimistic outlook on the system than do the sex offenders. The stigma surrounding sex offenders is more severe and disparaging than that of women in relationships with incarcerated men. These women still live a freer lifestyle. It seems that regardless of society's treatment toward both, sex offenders attempt to overcome a much bigger obstacle; this could be attributed to the higher number of women embracing the cultural schema. Perhaps by making greater strides to attain the characteristics of the cultural schema, sex offenders can begin to make a case for themselves and prove to society that they should be viewed in a different light.

Furthermore, the chimerical schema (which includes blame and aspects of rationalization) is detrimental to an offender's case. As Kostiner states, "Changing people's unconscious assumptions seems almost an impossible task," and as sex offenders are a marginalized and stigmatized group of individuals, change amongst this group is even more of a challenge. Without losing hope, however, the author finds that the seemingly impossible may still be achieved (Kostiner 2003). Though it may not be instantaneous, embracing the cultural schema makes change a more possible task. In Hanson and Slater's 
study, therapists and probation officers were asked to sentence imaginary child molesters based on various accounts given. The study expressed, however, that even when people maintained their skepticism toward child molesters (therapists in particular), this did not translate into a more punitive sentence (Hanson and Slater, 1993). This demonstrates the possibility of change in the mind of society; while ambitious, not all individuals possess the same perspective on sex offenders as many sex offenders themselves assume. By displaying themselves in a more gentle and articulate light, they may gain a voice to speak out and make necessary changes in society.

Further research will be conducted in which oneon-one interviews with sex offenders will be carried.This will help obtain a better perspective of their outlooks and views on their offenses and current laws. I believe adding the chimerical schema to the three-schema approach, makes Kostiner's framework more applicable to society and to other marginalized groups. Since the cultural schema is the most ideal, change will likely occur for sex offenders through the adaptation and embracing of this schema. It is evident that clinging to the chimerical schema does not aid many offenders and only makes their situations worse. 


\section{BIBLIOGRAPHY}

De Young, M. 1988. “The Indignant Page:Techniques of Neutralization in the Publications of Pedophile Organizations.” In Child Abuse and Neglect, 12, 583-591.

Dutton, D.G. 1986. “Wife Assaulters' Explanations For Assault:The Neutralization of Self-Punishment.” In Canadian Journal of Behavioural Science, 18, 381-390.

Hanson, R.K. and S. Slater. 1993. "Reactions To Motivational Accounts Of Child Molesters.” In Journal of Child Sexual Abuse, $2(4), 43-59$.

Kostiner, I. 2003."Evaluating Legality:Toward a Cultural Approach to the Study of Law and Social Change." In Law \& Society Review, 37:†323-368.

Lin, Ann C. 1998. "Bridging Positivist and Interpretivist Approaches to Qualitative Methods." In Policy Studies Journal 26(I): 162-180.

Pollock, N.L. and J.M. Hashmall. 1991. “The Excuses of Child Molesters.” In Behavioral Sciences and the Law, 9, 53-59.

Schultz, Pamela. 2005. Not Monsters: Analyzing the Stories of Child Molesters. Lanham: Rowman \& Littlefield.

Scully, D. and J. Marolla. 1981. "Convicted Rapists' Vocabulary of Motive-Excuses and Justifications." In Social Problems, 31.530-544.

Taylor, L. 1972. “The Significance and Interpretation of Replies to Motivational Questions:The Case of Sex Offenders.” Sociology, 6, 23-39. 